\title{
EIX: Reducing Cycle Time in Thought Leadership
}

\author{
James Wetherbe (Texas Tech University)
}

\section{KEYWORDS: Educational Services, Social Media \& Networks, Entrepreneurship, Innovation, Organization, Information Technology, Research Methods.}

Time and money are two crucial resources, but they are significantly different. Money not used today can be saved and used later if we so choose. Time, on the other hand, marches on and gets used up with or without our permission. For example, withholding a good business idea shortchanges us of the value that could have been added while we sat on our innovation. And within academia, it takes far too long - sometimes one to four years -- for our research and ideas to see the light of day through being published in traditional academic journals.

But how can one to four years be reduced to one to four weeks and ensure peer review quality?

Entrepreneur and Innovation Exchange (EIX) is a thought leadership platform, launched in August 2014 and sponsored by the Schulze Foundation, aimed at providing a timely, innovative, robust, social-media learning resource for students and practitioners of entrepreneurship world-wide.

To quote Dick Schulze, founder of Best Buy and the Schulze Foundation: "The current success rate of entrepreneurial efforts is 1 out of 23. The goal of EIX is to improve that ratio."

The EIX platform is designed to harness several types of forces in order to generate high-quality knowledge in a disruptively fast manner. The EIX website makes it easy for users to register and make submissions of all types. Submissions are tagged, formatted and filtered in ways that make it easy for reviewers and editors to follow and find submissions within their areas of expertise or interest. A powerful feedback loop enables the users who make submissions to learn quickly about new reviews, editorial feedback, fixes and suggestions. All of these together will rapidly improve the quality of submissions.

An overview of EIX is provided below.

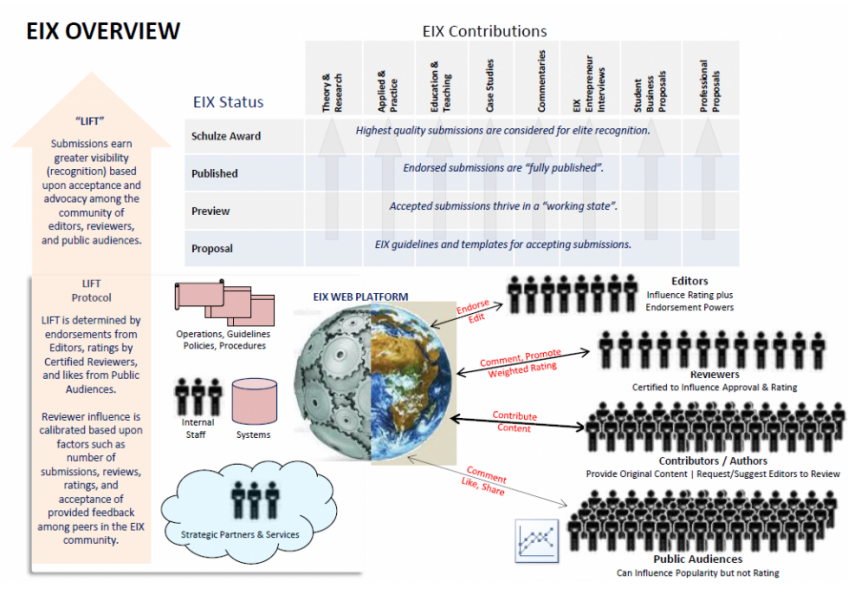

The EIX platform can be compared to the television shows "American Idol" or "Dancing with the Stars." Judges provide immediate reviews, followed by crowdsourcing feedback to complete the evaluation. The cream rises to the top based upon the combined feedback.

EIX represents a paradigm shift from traditional academic/practitioner print journals in several ways. It reduces the submission to publication time to a matter of days, by replacing the prolonged centralized, blind review process with a decentralized, transparent endorsement process. In this model, authors can request review by an editorial board of highly regarded scholars or entrepreneurs. Three endorsements from the editorial board grants acceptance for publication. To ensure quality, endorser's names are printed with the article, as an endorser, so their reputation is part of the equation. Also, all articles accepted for publication are given quality editing to ensure an engaging presentation.

Other innovations of EIX include: 
1. Traditional journal page limitation no longer applies, since the web allows for instant publication of more articles, whatever the length. This means EIX can publish more articles and more variety-research, practitioner, educational, case studies, commentaries and entrepreneurial proposals.

2. One-way communication traditional printed journals are replaced with online blogs allowing comments and debate among authors and readers, leading to scoring and ranking of articles.

3. Limited access to traditional print journals is resolved by sharing online links to articles and references, including social media links.

4. To overcome the "too many articles and not enough time" challenge for the public audience, EIX will use "crowdsourcing" to identify the most read and liked articles on different topics. Also, participants in the EIX platform can specify their topics of interest and be alerted via email or text when a new article or video of interest is published.

5. To overcome the perceived prestige advantage of print journals, authors of top-ranked EIX articles will be granted Schulze Award Scholarships to award to students of the authors' choice. Authors will be invited to present at an annual EIX conference held at the Schulze School of Entrepreneurship.

6. Beyond printed articles of traditional journals, EIX will have videos of thought-leading interviews, speeches, courses and company stories as well as entrepreneurial proposals from students and practitioners.

\section{National Profile and Prestige: Critical Success Factor}

A critical success factor for institutions of higher education is prestige, which attracts faculty, students and philanthropy. EIX achieves this through its editorial board and intellectual contributions from thought leaders from leading universities, entrepreneurs and consultants nationwide.

To facilitate rapid development, EIX has operated independently of the Schulze School of Entrepreneurship at the University of St. Thomas as a skunkworks project and been funded as a philanthropic initiative by the Schulze Foundation. The international profile will be sustained by an institutionally diverse editorial board so that EIX is postured as affiliated with St. Thomas but operationally independent.

Though EIX will initially focus on research, practitioner and educational articles with cases and entrepreneur interviews, the plan is to expand it into a broader learning resource, including online courses and entrepreneurial proposals. The pervasiveness of information and learning resources on the Internet creates an "open book exam" world. Reliance on brick and mortar libraries and institutions are no longer the only sources of education. Those motivated to learn can educate themselves. EIX will provide open book resources for entrepreneurs.

\section{"Sea Change" in Education}

This open book phenomenon is causing a "sea change" to expand learning through lower cost, non-traditional methods (e.g., MOOC's). But the drawbacks of these pure online student experiences is that students only experience the lecture - a pedagogy that dates back to the Medieval age -- and don't have the chance to learn from one another while the instructor moderates. We propose that even for classroom students, recurring lectures should be digitized and, like books, be available 24/7 before and after class. This will make lectures as cost-effective, accessible and convenient as having a hit stage show on video, saving the expense and access limitations of attending the same musical on Broadway. The classroom should be used for interactive action learning and class discussions, drawing from books and video lecture learning.

Another problem with online learning is the credential status of its certificate/degrees can also be vague, though this hasn't stopped new online "universities" from proliferating through extensive advertising. When thousands of students can register in an online course the cost per student is obscenely low -- but so is the student success rate. Nonetheless, in business and education, it is the outliers (e.g., Amazon.com, Udacity, Minerva and University of Phoenix) that create paradigm shifts. These should not be ignored.

As a forthcoming feature, EIX will provide a platform for online courses taught by top professors from other universities, by providing a library of courses available $24 / 7$ on the EIX platform. All universities should aggressively pursue this chance to create a presence in this emerging Internet education platform, along with developing their traditional programs, and sharing 
courses with other universities.

Though the cost per student is low, the dropout rate of online-only universities is over $95 \%$. It is not motivating to listen to video lectures alone, study without the support and encouragement of peers, or worry about whether your online degree will be worth anything in the job market. But a combination of intense, cohortresident education supplemented with online distant learning offers a hybrid solution for peer-driven collaborative learning.

Of course, traditional resident academic programs at universities such as St. Thomas are still important, especially for traditional high school graduates who need to mature and build new social connections. However, the growing number of non-traditional students can benefit greatly from specialized, innovative niche courses and degree programs.

\section{Summary}

In summary, EIX, using social media, will speed up the reviewing and publishing process for thought leaders in entrepreneurship, and encourage the disruptively fast sharing of ideas. Further, it will use social media to share ideas of specific interest to EIX users, and provide a grass roots approach to develop and spotlight the ideas that are new and trending among the academic and practitioner entrepreneur community.

Additional Search Terms: publishing, online publishing, academic journals, journals, social media 